\title{
A LITERATURA INFANTIL INSTIGANDO QUESTÕES "DELICADAS" DESDE A INFÂNCIA: O CASO DE BINTOU'S BRAIDS
}

\author{
Patrícia Pinheiro Menegon * \\ Josilene Pinheiro-Mariz **
}

\begin{abstract}
Resumo: Compreendendo que a literatura é um dos meios mais eficazes para se estimular o imaginário da criança quando de sua entrada na escola, buscamos discutir a noção de beleza negra infantil e a relação entre avós e netos, pelo olhar da cultura africana, a partir da narrativa Bintou's Braids (DIOUF, 2001) na aula de inglês. As nossas reflexões estão ancoradas em Hunt (2010) e outros, ao tratarem da necessidade de se iniciar a criança na literatura desde cedo na escola; na Lei 10.639/03, que torna obrigatório o ensino da História e Cultura Africana e Afro-brasileira no ensino básico, como incentivo à leitura; em Munanga (2005) sobre o racismo na escola; e, em Hooks (2006) no que concerne à beleza negra.
\end{abstract}

Palavras-chave: Literatura infantil. Cultura africana. Beleza.

\begin{abstract}
Understanding that literature is one of the most effective ways to stimulate the imagination of children when they enter school, we discuss the notion of black beauty child and the relationship between grandparents and grandchildren, by the view of African culture, from the narrative Bintou's Braids (DIOUF, 2001) in the English class. Our thoughts are anchored in Hunt (2010) and others on the need to introduce the child in literature from an early age in school; in the Law 10.639 /03, mandating the teaching of History and Culture African and Afro -Brazilian basic education as a tool to encourage reading ; in Munanga (2005) about blacks in Brazil (2004); and Hooks (2006) concerning the black beauty .
\end{abstract}

Keywords: Children's literature. African culture. Beauty.

\section{Introdução}

$\mathrm{Na}$ atualidade, os livros infantis produzidos a partir de uma nova demanda social atraem cada vez mais a atenção das crianças. A indústria editorial voltada para essa faixa etária produz livros que possibilitam estimular o imaginário, correspondendo, assim, aos anseios da criança leitora, com histórias que, de certa forma, concretizam uma relação de aproximação entre a realidade do pequeno leitor e a mensagem contida no livro. No âmbito da aprendizagem de uma língua estrangeira não é diferente, havendo, nesse contexto, uma infinidade de recursos que estimulam a leitura e a criatividade infantil.

Faz-se necessário discutir e ratificar que a entrada da criança na escola é um importante momento de sistematização da aprendizagem, pois se trata de uma delicada etapa da formação humana, uma vez que nesse momento que a criança se confronta com o novo, a partir de sua própria visão de mundo, do seu próprio olhar. Daí, portanto, o papel da escola promover em esse estímulo, enquanto elemento essencial para o desenvolvimento infantil.

Um dos recursos para se estimular esse desenvolvimento, na atualidade, é a aprendizagem da língua estrangeira, sendo em maior quantidade ofertada a língua inglesa.

Entendemos que a sala de aula se constitui em um espaço sine qua non para estimular a curiosidade por mundos diversos e distintos. Nesse campo, também, os livros infantis tem papel fundamental, sejam eles livros didáticos, sejam paradidáticos. $\mathrm{O}$ fato é que de uma maneira geral, a beleza da ilustração e mesmo as histórias trazidas nos livros ou álbuns

\footnotetext{
* Mestre pelo Programa de Pós-Graduação Mestrado Interdisciplinar Cultura e Sociedade - PGCULT da Universidade Federal do Maranhão (UFMA). Professora do Ensino Básico da rede privada em São Luís-MA. Endereço eletrônico: patriciamenegon21 @ hotmail.com

** Mestre e doutora em estudos Linguísticos Literários e Tradutológicos (USP); Pós-doutorado pela Universidade Paris 8. Professora da UFCG. Endereço eletrônico: jsmariz22@ hotmail.com
} 
infantis são determinantes para estimular o imaginário infantil, despertando os mundos recônditos da criança.

Estudiosos como Hunt (2010) e Poslaniec (2002) ressaltam a importância da literatura infantil com seu papel chave de estimular o imaginário. Nesse mesmo sentido, Reys (2010) chama a atenção para a necessidade de, logo no início da aprendizagem, se propor atividades que estimulem a fantasia infantil, enquanto principal elemento de estímulo à rede criativa que se instaura nesse universo, desde que tal estímulo seja feito a partir de certo conhecimento de mundo da criança. É nesse contexto que identificamos em atividades lúdicas como as contações de histórias, por exemplo, como componente de estímulo ao imaginário infantil, posto que mesmo na esfera do ensino/aprendizagem da língua estrangeira (LE), é necessário que essa atividade também seja desenvolvida.

Partindo dessas reflexões e intentando incitar a capacidade da criança, Lima e Pinheiro-Mariz (2012) chamam a atenção para a formiga, como uma personagem presente em diversas fábulas do francês La Fontaine. Dentre as inúmeras, destacam: La cigale et la fourmi, La colombe et la fourmi e La mouche et la fourmi. ${ }^{2}$ Nesse caso, tem-se um exemplo de como se pode instigar a criança a refletir, por exemplo, sobre a preservação do meio ambiente, a partir de textos literários, nos quais há personagens-animais conhecidos pelas crianças, sendo, portanto, uma porta para o estímulo a outros universos do infante.

É a partir desse domínio no qual subjazem elementos já conhecidos do universo infantil que embasamos estas reflexões. Propomo-nos, então, a traçar ponderações sobre o papel da narrativa infantil, Bintou's Braids, (2001) [traduzido para o português do Brasil como As tranças de Bintou] (2004), da escritora franco-senegalesa Sylviane Diouf, como um caminho para se discutir questões, por assim dizer, delicadas logo na infância. Sob o nosso prisma, a questão da beleza africana/beleza negra é um tema que precisa ser debatido nos primeiros anos da formação escolar da criança, pois, quando retomamos a noção de que a entrada na escola é um momento fundamental na formação humana, vislumbramos um importante período de formação de uma consciência menos preconceituosa. Tal comportamento pode ecoar em outras áreas da vida da criança, e, por essa razão, enfocamos a beleza sob o olhar da menina Bintou, personagem central da narrativa; ressaltando também a ótica de sua avó, enquanto representação da sabedoria africana.

Outra questão que discutiremos aqui é a relação entre a avó e a neta, levando-a em conta como elemento sócio cultural intrínseco à cultura africana. É necessário ressaltar que, sócio historicamente, o idoso é o guardião do conhecimento, lembrando-se também que, ainda nos dias de hoje, a hierarquia africana tem no mais velho, o alicerce social. Por isso, também lembramos também que questões sobre a identidade sócio-histórico-cultural, constituem-se como um elemento essencial na formação do cidadão. Tal viés pode ser acentuado, sobretudo no caso da aprendizagem de uma língua estrangeira, fortalecendo a importância de se discutir as relações com o outro, neste caso, enfocamos o ensino do inglês como língua estrangeira (doravante ILE), transpondo o foco da língua inglesa americana ou inglesa e levando-a para o continente africano, enquanto espaço de diversidade linguística também.

Para estas considerações, desenvolvemos um estudo bibliográfico e como ancoragem teórica, firmamo-nos nas ponderações de Munanga (2005) sobre a necessidade de se pensar no racismo no âmbito da sala de aula e em Florêncio e Pinheiro-Mariz (2016) no que concerne à urgência em se trazer questões delicadas como perdas, pois entendemos que tais discrições nos dão o suporte necessário para refletir sobre questões delicadas como o racismo, a partir de uma leitura de Bintou's Braids. As nossas cogitações mostram que propor discussões para crianças ressalta a necessidade de se trabalhar desde cedo questões como o racismo contrapondo-se à beleza. Além disso, esta atividade realça a importância de se

\footnotetext{
${ }^{2}$ A cigarra e a formiga, A pomba e a formiga e A mosca e a formiga. Todas essas fábulas são facilmente encontradas em publicações impressas ou digitais ou ainda online.
} 
atender à Lei 10.639/03, que torna obrigatório o ensino da História e Cultura Africana e Afrobrasileira no ensino básico não apenas como instrumento de incentivo à leitura literária e à formação do jovem leitor; mas, sobretudo, como ferramenta de conscientização da igualdade entre as pessoas, independentemente da raça, mesmo que esse espaço seja o da aprendizagem de uma LE, conforme nos exemplificam Florêncio e Pinheiro-Mariz (2016), ao discutirem sobre a necessidade de o professor de francês como língua estrangeira trabalhar a literatura africana para crianças no âmbito do ensino dessa LE, lançando um olhar especial para a delicadeza de temas como perdas, guerras e outras temáticas que, aparentemente, não pertenceriam ao universo da infância.

Ao selecionarmos excertos da obra para exemplificar as nossas percepções, optamos por apresentar os excertos na língua original do conto, pois na nossa ótica, é importante que professores de inglês como língua estrangeira possam discutir as questões subjacentes à obra, logo na infância e na língua em estudo, quando da aprendizagem dessa que é a principal língua estrangeira de ensino no nosso país. Com esse procedimento de discussão, ressaltamos que no papel de professores de línguas estrangeiras também somos agentes de possíveis mudanças, entendendo que, dessa forma, poderemos formar cidadãos capazes de propor modificações em realidades sociais diversas.

\section{Educação intercultural na formação infantil}

Profissionais que atuam na Educação Infantil sabem da importância da leitura literária desde cedo, posto ser compreensão unânime que a literatura é um instrumento essencial no estímulo ao imaginário de crianças de todas as idades. Para Hunt (2010, p. 43), por exemplo, "A melhor resposta: porque é importante e divertido"; para esse estudioso, é também necessário estudar a literatura infantil, pois além de tudo, diverte. É, muito provavelmente, por essa razão que a indústria editorial produz cada vez mais livros infantis atrativos, conquistando leitores em potencial de várias faixas etárias e essa situação é aguçada quando se trata do ILE ou de qualquer que seja a LE. Essa indústria voltada para a faixa etária infanto-juvenil produz, numa nova configuração econômica, livros capazes de corresponder, de alguma forma, aos anseios da criança-leitora, a partir de histórias que concretizam uma relação de aproximação entre a realidade do pequeno leitor e a mensagem ali contida.

Nesse contexto, e de uma maneira geral, a escola tem buscado apresentar às crianças o leque de possibilidades da literatura infanto-juvenil, em prol de uma formação leitora que, dentre outros aspectos, respeite a diversidade cultural e valorize essa criança como cidadão e ser histórico vinculado às peculiaridades de seu grupo sociocultural. Embora sejam percebidos os esforços da instituição escolar, é essencial que se desenvolva o hábito da leitura de obras que abordem temas menos discutidos como as temáticas étnico raciais. Mesmo quando estão presentes nas obras literárias infantis, parece que nem todos os professores debruçam-se sobre a possibilidade de refletir de modo mais efetivo a cultura africana. Pode-se inferir que, às vezes, tais demandas são preteridas em relação a outras ou por desconhecimento, descuido ou por falta de formação do professor para tratar da questão, uma vez que, seria necessário de modo até, natural, se discutir o tema racismo na escola, conforme afirma o antropólogo especialista, Kabengele Munanga (2005):

Os mesmos preconceitos permeiam também o cotidiano das relações sociais de alunos entre si e de alunos com professores no espaço escolar. No entanto, alguns professores, por falta de preparo ou por preconceitos neles introjetados, não sabem lançar mão das situações flagrantes de discriminação no espaço escolar e na sala como momento pedagógico privilegiado para discutir a diversidade e conscientizar seus alunos sobre a 
importância e a riqueza que ela traz à nossa cultura e à nossa identidade nacional. (MUNANGA, 2005, p. 16).

Para esse intelectual, o espaço escolar é um frutuoso local para se lidar com questões delicadas como a do racismo. Enquanto profissionais da educação, também observamos que, em diversos espaços escolares, "os preconceitos introjetados", no dizer do antropólogo, se manifestam com tanta naturalidade que, por vezes, esquecemos que estamos na escola para lidar também com essas questões. Logo, o ambiente escolar deve ser o principal motivador de transformações.

A implementação da Lei 10.639/03, no ano de 2003, de certa forma, pode ser responsável por algumas mudanças, ainda que sensíveis ou quase imperceptíveis, mas que por certo ainda virão, espera-se! Mas, e o professor de uma LE, como fazer para contribuir com as transformações necessárias para discutir e minimizar esses "preconceitos introjetados" se ele não dá aula nem de História, nem de Geografia e nem literatura? É importante lembrar que a sala de aula de LE é um dos ambientes mais profícuos para esse debate, pois no continente africano, há culturas de língua francesa, inglesa e espanhola, só para citar as línguas estrangeiras mais ensinadas no Brasil. Logo, esse é um lugar especial para se refletir sobre atitudes e comportamentos que precisam ser revistos.

$\mathrm{Na}$ atualidade - contemporaneidade ou pós-modernidade, sem entrar na discussão terminológica e conceitual -, quando a diversidade é uma das palavras na ordem do discurso, tem-se a impressão que ainda não estaríamos bem preparados para lidar com questões como a da africanidade, negritude ou com o racismo. Diariamente, veem-se manifestações discriminatórias e na escola não é diferente, pelo contrário, além de ser muito comum ali, parece não haver uma forma de se trabalhar tal temática. Para Munanga (2005, p. 15): "Essa falta de preparo, que devemos considerar como reflexo do nosso mito de democracia racial, compromete, sem dúvida, o objetivo fundamental da nossa missão no processo de formação dos futuros cidadãos responsáveis de amanhã".

Entendemos, portanto, que a nossa missão no processo ao qual se refere o intelectual, enquanto profissionais da área das Letras, é subsidiar possibilidades para que os nossos aprendizes sejam cidadãos menos preconceituosos e com um olhar mais amplo para o mundo, a partir da leitura de obras literárias. Assim, ancoradas nas Leis 10.639/03 sobre o ensino da cultura africana e afro-brasileira e na 11.645/08 que prevê um ensino de base intercultural na Educação Básica, tecemos reflexões com o olhar voltado para a narrativa Bintou's Braids, obra que muito embora não tenha o racismo como seu tema central, no contexto na sala de aula, essa questão aflora espontaneamente, pois a obra apresenta a beleza a partir das tranças da pequena protagonista, uma criança que questiona e busca as verdades implícitas nesses questionamentos.

As tranças de Bintou, na atualidade, é uma das histórias infantis mais lidas nas escolas e está entre as que mais têm sido indicadas por especialistas da educação, conforme foi possível observar desde o $1^{o}$ Seminário sobre Políticas de Ações Afirmativas $e$ Consciência Negra da Faculdade de Educação (FE) da USP, (2005), dado o seu valor enquanto obra que instiga a discussão de questões como a identidade negra, sem adentrar de maneira preconceituosa ou de julgamento de valor. Por isso, entendemos que Bintou's Braids pode ocupar um lugar especial na aula de inglês. Ela se insere, portanto, nas reflexões de Abdallah-Preitceille (2002), ao reforçar a importância de se formar cidadãos interculturais desde os primeiros anos escolares como caminho para uma educação sem ajuizamentos precipitados ou, dito de outra forma, cidadãos que saibam identificar e conviver com o diferente, sem se perceber como inferior ou superior ao outro. Para a estudiosa, em se tratando do espaço escolar, a literatura é o suporte mais potente para favorecer essa formação intercultural e é assim que entendemos o procedimento de ler a obra e tratar dessa questão na sala de aula de ILE. 
Ora, se é a fase da infância o melhor momento para se formar cidadãos conscientes e sem preconceitos, e se a literatura é uma senda especial para esse fim, é importante que a escola, enquanto elemento transformador haja em busca de mudanças que, de fato, operem a diferença na vida do cidadão em primeira formação.

\section{As bases legais para o ensino intercultural}

Há quase trinta anos, quando foi promulgada a Constituição de 1988, buscava-se uma sociedade democrática a partir do estabelecimento de relações igualitárias entre os diversos grupos sociais do espaço territorial brasileiro. Inclui-se nessa esfera, o espaço democrático escolar, enquanto local de diversidades subjetivas, sociais e coletivas resultantes de intersecções múltiplas como as de identidades, conceitos e valores entre seus membros.

Não obstante toda essa proposta que visava a paridade entre os membros da comunidade, observou-se que nas últimas décadas, houve uma crescente desigualdade nos processos educativos concernentes ao ensino intercultural, quando vinculado às expressões e práticas sociais de compreensão da cultura brasileira. A exemplo disso, o Movimento Negro -, como é genericamente conhecido o conjunto dos diversos movimentos sociais afrobrasileiros, surgidos a partir da redemocratização no pós Segunda Guerra Mundial-, reivindica o reconhecimento da contribuição da cultura africana na formação da atual sociedade brasileira. Cabe à escola, portanto, oferecer os primeiros alicerces para essa educação de base intercultural previstos na Lei conforme destaca Camacho (2007).

[...] a promulgação da Lei 10.639/03 - que altera a Lei de Diretrizes e Bases da Educação Nacional (LDB) e inclui no currículo oficial dos estabelecimentos de ensino básico das redes pública e privada do país a obrigatoriedade do estudo da temática "história e cultura afro-brasileira" - é essencial para eliminar a desigualdade presente no sistema educacional brasileiro. A lei se torna efetivamente mais importante e orgânica porque sabemos que foi fruto de demandas e lutas históricas dos grupos que enfatizam a necessidade da implementação e continuidade de políticas que procuram reparar os danos causados por séculos de violência racial e discriminação. (CAMACHO, 2007, p. 08).

A fim de minimizar esses "danos causados por séculos de violência racial", a Lei Federal que já tem quase quinze anos, ainda parece estar longe de sua efetivação. Isso é observado empiricamente, pois para todo e qualquer professor/educador que trabalha na rede pública ou mesmo na esfera privada, são perceptíveis as barreiras encontradas para se fazer concretizar a tal Lei. A discriminação à qual se refere Camacho (2007), é sentida e ressentida cotidianamente nas escolas, de modo velado e, em outras ocasiões de maneira explícita, sobretudo nos primeiros anos da infância, momento que, sob a nossa ótica, é o mais propício para se discutir a questão da equidade, sobretudo, a do racismo, pois o nosso país é originado da miscigenação de povos oriundos de, pelo menos, três continentes: América, Europa e África.

Assim, questionam-nos, portanto, sobre o fato de se ler, na escola, -de maneira regular e sistematizada- tradicionais histórias oriundas de culturas europeias, como: Chapeuzinho Vermelho ou Branca de Neve, apenas para citar dois exemplos, imortalizados ainda mais pelo americano Walt Disney. Por que, no Brasil, traduções/adaptações de clássicos como os da marfinense Fatou Keita (2015) ou do congolês Jorus Mabiala (2009) que transpuseram para a África esses personagens, tão tradicionais no cânone brasileiro, não 
ocupam o mesmo espaço nas livrarias? Seria apenas uma questão de oposição entre o tradicional e o moderno? Ou vai muito além disso?

O conceito de ensino de base intercultural é um caminho eficaz para a aproximação harmônica entre culturas distintas; isto é, quando cotejadas, não há uma cultura superior à outra. Ambas podem conviver harmoniosamente, sem que um seja apagado pelo outro. É por essa razão que a educação na perspectiva intercultural prevê o conhecimento dos modos de viver e refletir das outras culturas como via para trocas culturais. Evidentemente, para se compreender o intercultural como troca entre culturas, seria interessante discutirmos a noção central que é a de cultura, todavia, delimitaremos esse conceito enquanto foco de análise, conforme Francisco (2006, p. 123) que afirma que a cultura é mais que "particularismo simbólico, consistindo em campo de mediações simbólicas pelas quais um grupamento humano compreende/apreende o real. Essas mediações simbólicas são o fundamento de uma questão que não é nova - a questão da identidade".

Quando intentamos vislumbrar os processos educativos baseados em trocas interculturais, concretizamos a oportunidade de "agirmos no mundo de maneira aberta ao diálogo e à aproximação entre diferentes lugares e pessoas" conforme afirma Paraquett (2012, p. 217). Há de se ressaltar que além de se observar essa perspectiva como salutar e, portanto, necessária para uma melhor convivência entre pessoas, trata-se também de uma orientação legal. Tal essência permite a constatação de que o objeto em estudo é parte das realidades mais amplas e complexas no plano histórico, cultural e social conforme preceitua a Lei:

Art. $1^{\circ}$ - A Lei $N^{\circ}$ 9.394/1996 passa a vigorar acrescida dos seguintes Arts. 26-A, 79A e 79-B:

Art. 26-A - Nos estabelecimentos de ensino fundamental e médio, oficiais e particulares, torna-se obrigatório o ensino sobre História e Cultura AfroBrasileira. $\S 1^{\circ} \mathrm{O}$ conteúdo programático a que se refere o caput deste artigo incluirá o estudo da História da África e dos Africanos, a luta dos negros no Brasil, a cultura negra brasileira e o negro na formação da sociedade nacional, resgatando a contribuição do povo negro nas áreas social, econômica e política pertinentes à História do Brasil. § $2^{\circ}$ Os conteúdos referentes à História e Cultura Afro-Brasileira serão ministrados no âmbito de todo o currículo escolar, em especial nas áreas de Educação Artística e de Literatura e História Brasileiras. (BRASIL, 2008).

Valer-se do amparo legal para a implementação de uma formação de base intercultural significa assegurar que as Leis 10.639/03 e 11.645/2008 ultrapassam um espaço normativo e se constituem em um avanço na inserção de uma visão mais coerente da cultura africana no espaço plural da sala de aula. Porém, para além da disciplina da esfera legal, a aplicabilidade dessa lei enfrenta desafios facilmente perceptíveis no que se refere aos entraves de trabalhar a cultura africana, por exemplo, no ambiente escolar. Desses entraves decorrem todas as problemáticas observadas quando se pretende desenvolver um ensino com significados interculturais por meio da leitura de textos literários.

No tocante à reflexão sobre as atividades da leitura, sabemos que a competência comunicativa envolve saberes relativos às múltiplas capacidades. Para Jouve (2002), por exemplo, tais saberes e habilidades promovidas pelo processo da leitura estão enfocados em cinco dimensões: 1) processo neurofisiológico, a leitura é um ato em que se desenvolve a partir do funcionamento cerebral, que opera na percepção, identificação e memorização dos signos; 2) processo cognitivo, o leitor se concentra no encadeamento das ideias e por meio da cognição avança na interpretação do texto; 3) processo afetivo, onde a recepção é um componente essencial, que permitirá ao leitor se identificar com o texto para prosseguir ou interromper a leitura; 4) processo argumentativo, o leitor reflete sobre o sentido do texto e, a 
partir de então, adota ou não a argumentação apresentada; 5) processo simbólico, a leitura interage individualmente com o leitor que passa a identificá-lo do seu contexto cultural.

Quando levantamos a hipótese de leitura de contos africanos para promoção da interculturalidade estamos levando em consideração que em se tratando dos países africanos, o que prevalece em matéria de cultura, desloca-se do escrito para o oral. Para Aguessy (1977, p. 95), isso implica dizer que "diferentemente do que ocorre com o pensamento ocidental, o qual pode orientar-se a partir das mais diversas fontes de referências escritas [...], a tradição africana é veiculada, principalmente, pela oralidade".

Com esse olhar, passamos a uma leitura da obra que se coloca como capital na educação intercultural, uma vez que a narrativa põe em destaque características essenciais para se valorizar a cultura africana, confluindo para a apreciação da cultura afro-brasileira. Ressalte-se que em relação à África, além do fator tradição oral, adiciona-se a ele uma questão que, por vezes, é muito pouco tocada na escola, posto ser um tema que demanda do professor apropriado conhecimento para saber lidar com a temática do racismo, conforme nos sinaliza Munanga (2005). Passamos, então, à leitura de Bintou's Braids.

\section{Bintou's Braids, de Sylviane Diouf: uma leitura em busca da valorização da beleza negra e da sabedoria do velho}

Historicamente, o continente africano é marcado pela tradição oral, que ganhou vida nos velhos daquele continente, os griots. Essa realidade sofreu transformações com a chegada do colonizador europeu, que passou a registrar, na escrita, as histórias que eram repassadas de geração em geração; portanto, o colonizador inseriu na cultura africana o modelo tradicionalmente europeu. É certo que na Europa, ao longo de muitos anos, a oralidade também foi fundamental para o desenvolvimento da cultura literária, por exemplo. Um evidente exemplo disso são os trovadores, poetas que, na maioria das vezes, não se comunicavam por escrito, sendo necessária a presença do copista, aquele que registrava os versos do trovador. Nota-se com isso que, mesmo em uma tradição trovadoresca, para o Europeu, a escrita sempre pareceu ser indispensável como registro cultural, ao contrário do que marca uma tradição no continente africano. Assim, o colonizador inseriu na África, a escrita, muito embora a tradição oral tenha permanecido ainda hoje.

Atualmente, esse misto de oralidade e escrita é conhecido como 'oratura' ou 'oralitura' (LEITE, 2010), pois há diversos escritores que são inspirados da tradição oral para compor sua produção literária. Um exemplo de escritor com essa característica é Mia Couto que, em diversas obras, faz narrativas de episódios tradicionais, conforme pode ser visto em suas narrativas; é nesse âmbito que se insere a história As tranças de Bintou. É interessante ressaltar que a sua autora é filha de mãe senegalesa e pai francês e viveu na França, Gabão, Itália e, hoje, mora em Nova York, onde mora e trabalha como editora da Ohio University Press e também da National Geographic e, em ambas, é responsável pelas discussões de diásporas africanas, além de ser escritora de ensaios e obras de ficção, sobretudo para crianças. Essa vivência da autora, em realidades distintas dá um peso cultural à obra em estudo, uma vez que, em tendo vivenciado diversas situações culturais, ela também pôde observar as diversas condições do negro em idades diferentes, como no caso da pequena protagonista de Bintou's Braids ${ }^{3}$.

Assim, para esta leitura procuramos relacionar os processos de construção dos sentidos da narrativa às condições culturais das crianças brasileiras, pensando nas relações interculturais, nas quais não se observa culturas superiores ou inferiores, mas, possibilidades

\footnotetext{
${ }^{3}$ Optamos por utilizar por vezes o título no original, por vezes, na tradução pois entendemos ser importante marcar que se trata de uma narrativa repercute para além de um ambiente monocultural e monolinguístico.
} 
de se promover diálogos entre elas. Considerando, então, a importância da literatura africana na promoção de uma educação intercultural e adotando essa relação como objeto destas reflexões, nestas análises, buscamos responder às seguintes perguntas: de que forma a escola trabalha as temáticas da diversidade étnica e racial que emergem nas rodas de leitura? Como a literatura africana pode contribuir para a afirmação de uma identidade cultural que aproxime as realidades de crianças brasileiras e africanas? A leitura de contos africanos pode promover o ensino de base intercultural conforme normatiza a lei?

IMAGEM 1: Bintou se apresenta

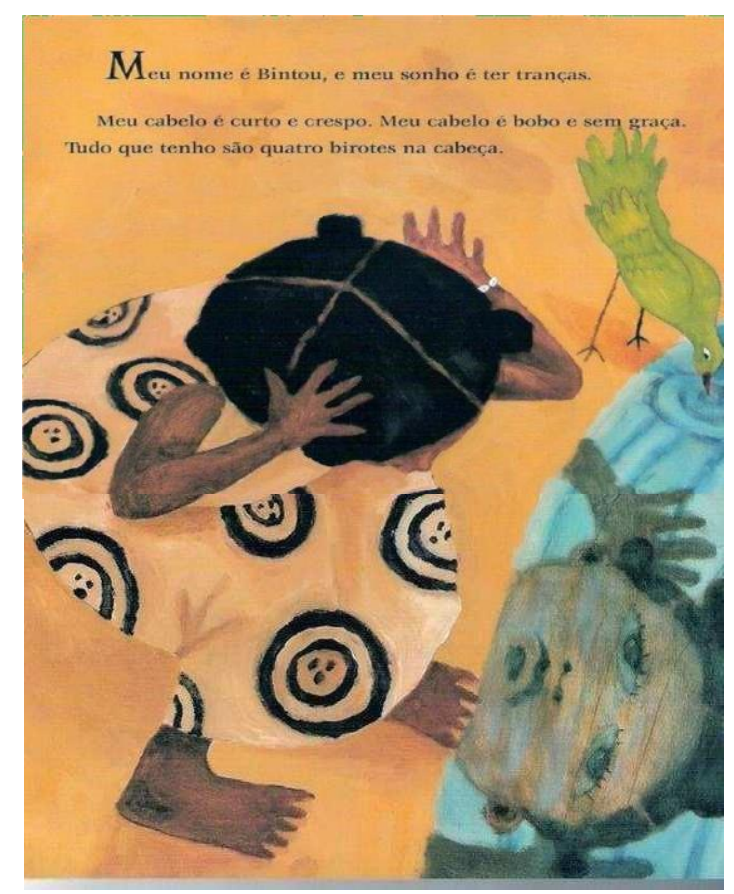

FONTE: As tranças de Bintou, (DIOUF, 2004, p.2)

My name is Bintou and I want braids.

My hair is short and fuzzy. My hair is plain and silly.

All I have is four little tufts on my head. (DIOUF, 2001, p. 1). ${ }^{4}$

Ao ler o incipit desta narrativa, percebe-se que a protagonista parece estar insatisfeita com seus cabelos, o que não é nenhuma novidade, particularmente, para as mulheres, pois os cabelos são, por um lado, devotado tema para poemas e canções; mas, por outro lado, constitui-se também em um constante desafio para a mulher. Aquela que tem cabelos lisos, os quer cacheados, quem os tem cacheados, os quer lisos; ou, na atualidade, quem tem os cabelos lisos, busca alisá-los ainda mais e quem tem os cabelos cacheados, quer deixá-los mais cacheados ainda. Observa-se, com isso, que parece ser, basicamente, a textura dos cabelos o grande fator de inquietação feminina. $O$ fato é que não é em vão que a antropóloga americana Bell Hooks (2006) tem se debruçado sobre a discussão do tema, lembrando que para a mulher, cuidar dos cabelos é um momento de intimidade, no qual, os homens são totalmente excluídos.

No caso de nossa pequena protagonista, o incipit leva o leitor a crer que esse seria o motivo de sua insatisfação, pois ao afirmar: My hair is short and fuzzy, dá-nos a impressão de

\footnotetext{
${ }^{4}$ Optamos por utilizar a tradução e imagens da publicação em português, por Charles Cosac, em 2004, pela editora Cosac Naify.
} 
haver certa ansiedade quanto a esse ponto. Para a maioria das mulheres com essa inquietação, facilmente ela seria resolvida, alisando-se os cabelos "fuzzy"; porém, logo em seguida, Bintou deixa claro o que a incomoda: ela quer apenas ornar os cabelos, o que também é próprio da maioria das mulheres e, contemporaneamente, as meninas também acompanham esse desejo: o de ser bonita, trazendo cores para o adorno dos cabelos. De um modo geral, no continente africano ou mesmo em outros espaços, a utilização das cores é bastante comum. Para a criança, de qualquer lugar do mundo, é fundamental.

No caso dessa primeira imagem do álbum, observa-se o quanto é importante ratificar para a criança brasileira, a importância da trança, enquanto elemento de estética da beleza negra. Trata-se de um valor repassado às gerações e, que no caso desta narrativa pode mobilizar os nossos valores de estética e de beleza. Ao pensar nos cabelos encaracolados como elemento da beleza negra, o professor de ILE estará conduzindo a criança a compreender que, na verdade, não existe o feio e o bonito e sim, formas distintas de se ver o outro e a si mesma. Retomamos, nesse ponto, a consistente discussão de Munanga (2005) ao lembrar que, grosso modo, o negro é apresentado nas mídias como bandido ou quando estão na ficção, os papeis dados a ele são de subalternos ou de vilões ao contrário dos brancos. Isso pode ratificar que a escola, - leia-se professor, em muitas situações -, se sente despreparada para lidar com a situação, uma vez que essa imagem arraiga-se no imaginário do povo brasileiro. Uma narrativa como a desta menina pode ser um elemento motivador para instigar a reflexão sobre as formas de beleza distantes daquela que foi estabelecida como padrão. Nesse caso, desenhos como o do ogro Shrek podem ajudar na desconstrução de estereótipos de beleza firmemente consolidados ao longo da construção da história da cultura ocidental e imortalizados pelos clássicos de Walt Disney, no qual a princesa é sempre loirinha de olhos verdes ou azuis e o príncipe é também loiro e forte.

Porém, se voltamos aos cabelos crespos de garotinha Bintou, naturalmente, seremos levados às reflexões que trazem à tona as constatações de Hooks (2006, p.7): "Certo número de mulheres afirmou que essa é uma estratégia de sobrevivência: é mais fácil de funcionar nessa sociedade com o cabelo alisado. Os problemas são menores; ou, como alguns dizem, 'dá menos trabalho' por ser mais fácil de controlar[...]". Pensar em estratégia de sobrevivência logo na infância parece ser duro e desnecessário para a criança, entretanto, quando estudamos um pouco mais as narrativas africanas endereçadas às crianças, percebemos que configura-se em uma necessidade levar a criança a perceber o peso do cotidiano pelo prisma da ficção. Isso foi percebido, por exemplo, no estudo da narrativa Ayanda, la apetite fille qui ne voulait pas grandir, da escritora marfinense, Véronique Tadjo, (FLORÊNCIO; PINHEIRO-MARIZ, 2016) quando a premiada autora de literatura infanto-juvenil expõe a perda de um ente querido para a guerra, confirmando-se a realidade da criança face à guerra.

Mas, na ótica de Hooks (2006), a estratégia de sobrevivência pode ser o controle dos cabelos crespos pela prática do alisamento. Porém, muito provavelmente, não era esse o 'controle' que a garota buscava, pois, logo em seguida, ela afirma:

Sometimes, I dream that little birds make their nest in my hair. It would be such a nice place for babies to rest. There, they would sleep and they would sing. But most of the time, I dream of braids. Long braids with gold coins and seashells. (DIOUF, 2001, 1). 
IMAGEM 2. o sonho de Bintou

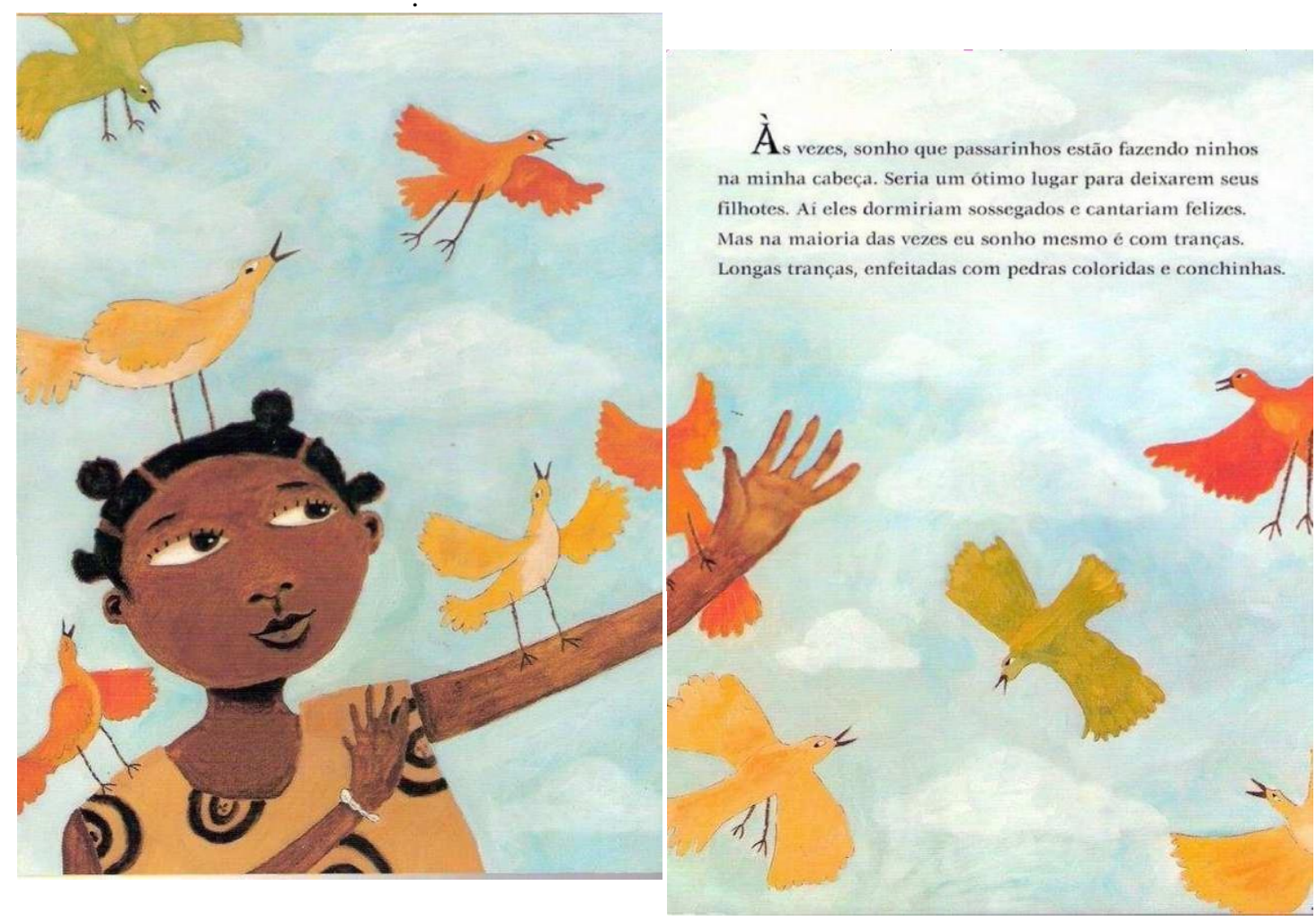

FONTE: As tranças de Bintou, (DIOUF, 2004, p. 3;4)

Dentro de certa insatisfação, percebe-se que a protagonista sonha. Não com os cabelos lisos, mas com pássaros e cores, afastando-se do que a antropóloga americana diz sobre a relação entre as mulheres negras e os seus cabelos crespos. Bintou não quer controlar os cabelos, alisando-os. Ela quer tão somente longas tranças, seu maior sonho. Provavelmente, o sentimento que a leva a achar seu cabelo sem graça, seja o elemento motivador do sonho pueril: "I dream of braids. Long braids with gold coins and seashells". Para ela, as tranças poderiam se enfeitadas e, por isso, teria a sua beleza ressaltada. Observamos outros agentes de motivação do imaginário quando ela cita as cores e também os pássaros: "Sometimes, I dream that little birds make their nest in my hair. It would be such a nice place for babies to rest". Os pequenos pássaros teriam um lugar ideal para cantar sossegados. Neste caso, este conto além de provocar uma discussão sobre o racismo e a beleza negra sem os cabelos alisados, pode igualmente estimular o respeito aos animais e ao meio ambiente.

É necessário frisar que a leitura de contos africanos requer também a compreensão de aspectos como a ancestralidade, o valor do idoso e a importância da palavra como elementos que ajudam a compor a cosmovisão africana e, em se tratando de Bintou's Braids, trata-se de um dos contos que melhor apresentam tais nuances como por exemplo a relação entre a criança e a pessoa idosa, além de, evidentemente, apresentar elementos que retratam uma cultura não muito conhecida por crianças brasileiras. Neste momento, queremos ressaltar o valor do idoso:

Grandma Soukeye knows everything. That's what my mother says. She says old people know so much because they have lived such a long time and have learned more than anybody else. Since Grandma knows everything, I ask her why little girls can't have braids. 
"A long time ago, there was a young girl named Coumba who thought only about how pretty she was," she says while stroking my head. "Everyone envied her and Coumba became vain and selfish. It was then that the mothers decided that little girls would not be allowed to have braids, so that they would only make friends, play and learn. From then on, Coumba got cornrows."

Grandma pulls gently on my ear and says, "Now, little Bintou, when you're older, it's fine to want to look your best and show everybody that you have become a young woman. But you are still just a girl. You will get braids when it is time." (DIOUF, 2001, p.1)

IMAGEM 3: a relação de Bintou com sua avó

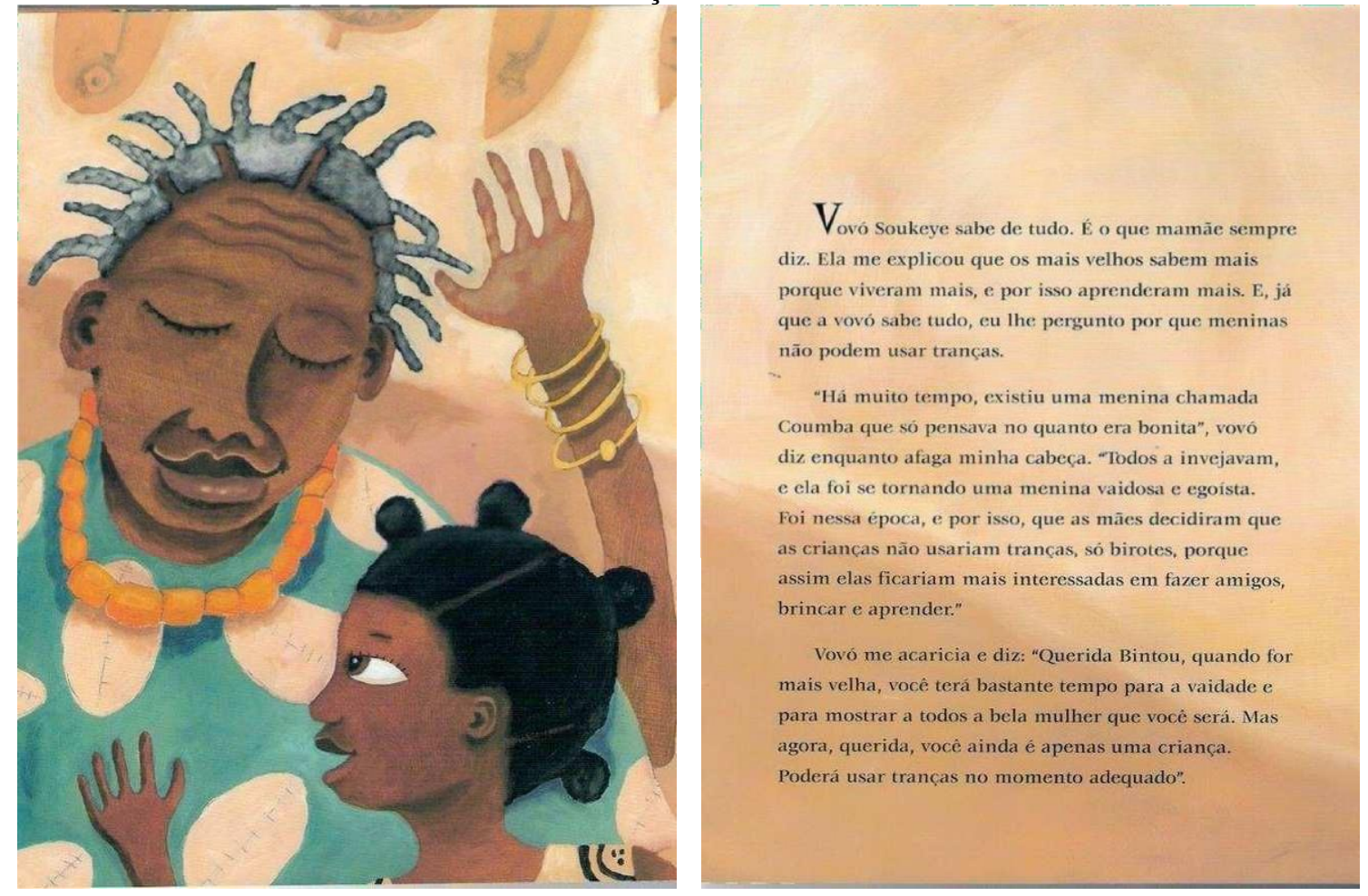

FONTE: As tranças de Bintou, (DIOUF, 2004, p. 9;10)

Grandma Soukeye knows everything. Para essa garota, a sua avó conhece todas as coisas. É ela quem sabe de tudo, como tradicionalmente o velho africano, pois já viveu mais que os outros, está mais próxima de seus antepassados e, portanto, têm os conselhos necessários para qualquer pessoas. A avó, Soukeye, pode resolver o problema de Bintou e começa explicando o porquê de a criança usar birotes e não tranças, pois as tranças são reservadas às mulheres, posto ser um instrumento de embelezamento feminino, não devendo ser de uso das meninas, uma vez que crianças não precisam mostrar a beleza, precisam brincar. "But you are still just a girl. You will get braids when it is time”. Essa seria, portanto, uma das principais lições deixadas por Soukeye e, neste caso, o impacto mimético da literatura sobressai ao pensarmos no quanto foi discutida essa problemática nos anos de 1990 em nosso país. Nesse decênio, houve certa polêmica entre antropólogos, a Igreja, enquanto instituição e uma apresentadora de TV de um programa "dito" para crianças e que, segundo os movimentos considerados mais "tradicionais", incitava a entrada da criança no mundo adulto, precocemente. A narrativa enfoca, exatamente, essa perspectiva de que a criança deve aguardar o seu momento de adulto; a menina chegará ao seu tempo de ser mulher. 
Um ensino para que a criança entenda que tudo tem o seu tempo e a infância é o momento de brincar e sonhar, sem preocupações é percebido pela pequena Bintou:

IMAGEM 4: o novo sonho de Bintou
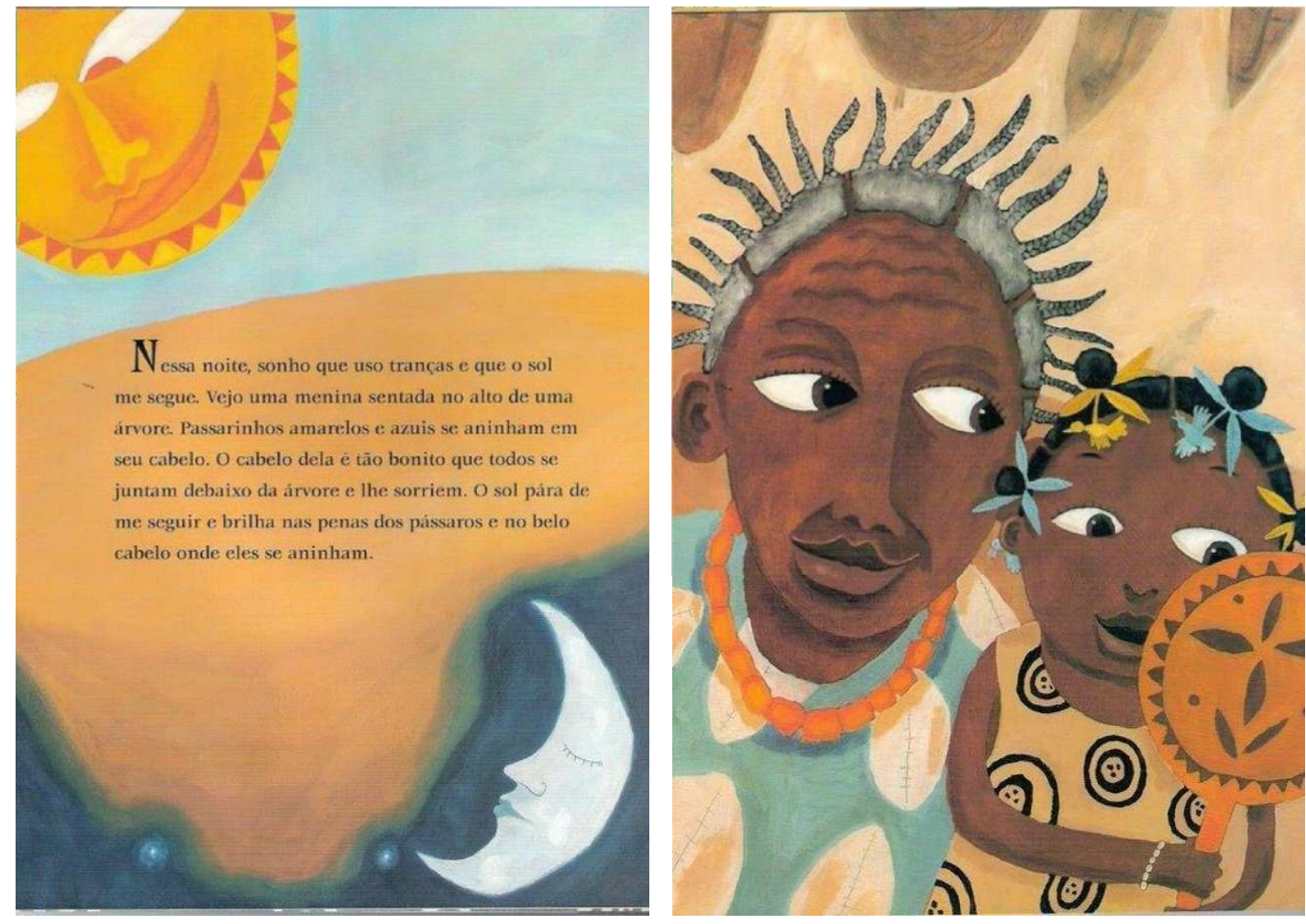

FONTE: As tranças de Bintou, (DIOUF, 2004, p. 23;24)

Tonight, I dream I have braids and the sun follows me. I dream I see a little girl sitting in a tree. Yellow and blue birds nestle in her hair. Her hair is so pretty that everybody has gathered under the tree and up at her. The sun stops following me and shines on the feathers of the birds and the pretty hair where they nest. (DIOUF, 2001, p.4)

Após o novo sonho, Bintou parece redescobrir-se em seu novo cabelo feito com todo o carinho de sua avó. Porém, não era simplesmente um sonho. Pode-se depreender desse momento da narrativa o quanto o idoso é valorizado na cultura de Bintou. Esse é um ensinamento que deve ser repassado às crianças: o respeito e a valorização dos mais velhos.

A narrativa, além de tudo, é um excelente caminho para também se descobrir um léxico que, de maneira geral, não aprece nos livros didáticos de ensino de inglês para crianças onde se tem, de um modo geral, apenas números, alfabeto etc. É também um espaço fundamental para se ensinar à criança que a língua inglesa está presente em mais de vinte países do continente africano, sendo, portanto um excelente início de descobertas das Áfricas.

A discussão e compreensão da narrativa é um processo no qual o leitor, por meio de competências individuais e estratégias, pode construir significados a partir da interação entre o seu conhecimento prévio e as informações contidas no texto. Portanto, quanto antes se começar a lidar com questões entendidas como delicadas, mais cedo o pequeno leitor terá a oportunidade de refletir sobre as mais diversas questões e confrontar suas ideias, argumentar sobre a realidade na qual o texto está inserido; pois, assim, pode haver, de fato, um alargamento de visões. 
Sob a nossa ótica, a leitura de contos africanos como recurso para a coerente difusão da cultura africana nas salas de aulas da educação básica, pode ser um caminho frutuoso para se minimizar estereótipos vinculados aos temas abordados quando se trabalha o africanismo na sala de aula. Por essa razão, as leis tornam obrigatório o ensino da história e cultura afrobrasileira e indígena no currículo escolar, estabelecendo que tais temáticas devam perpassar todo o currículo, mas de modo precípuo as disciplinas História, Literatura, Artes e Ensino Religioso. (BRASIL, 2008).

Assim, por meio de ações como uma abordagem de um conto africano de língua inglesa no contexto da aprendizagem, ações didáticas que abordem as questões étnico-raciais como aspecto essencial para a construção de sujeitos conscientes da diversidade cultural na sociedade moderna estarão em pauta.

\section{Conclusão}

Observamos que desde as séries iniciais do ciclo de alfabetização até a conclusão da educação básica, a escola preocupa-se com a oferta de leitura para os alunos. Porém, essa formação 'ledora' não está, em grande parte das vezes, vinculada a um ensino de base intercultural. $\mathrm{O}$ fator agravante nesse contexto se dá quando observamos o perfil econômico das crianças nessa faixa etária escolar, como pertencentes a uma moderna classe média, cada vez em maior expansão e consolidação no país.

A execução das atividades de leitura no ambiente escolar sublinha uma queixa constante entre os professores: a de que os alunos não gostam de ler. Para Kleiman (2011), esse quadro pode ser justificado pela ausência do hábito da leitura no ambiente de letramento ou também devido à formação precária de profissionais não leitores que precisam ensinar a ler e a gostar de ler. A tarefa de ler em sala de aula é vista como algo de difícil realização, pois na maioria das vezes, o professor a propõe para realizar outras atividades. Assim, essa prática acaba transmitindo para os alunos imagens negativas do livro e da leitura, desencadeando uma resistência a essa atividade.

A leitura de contos africanos tanto em aula de língua portuguesa, quanto no âmbito do ensino da LE, como a inglesa, pode ser vista e utilizada como aliada na adequada difusão da cultura africana e afro-brasileira. O desenvolvimento de ações que despertem um olhar sobre as questões étnico-raciais é, por conseguinte, fundamental para a construção de sujeitos conscientes da riqueza da diversidade da sociedade.

$\mathrm{Na}$ contemporaneidade, as pesquisas que investigam os processos vinculados às práticas educativas e socioculturais dispõem de diversas fontes para a busca e a análise de dados. Assim, tais pesquisas passaram a ser realizadas por meio de investigações qualitativas, uma vez que esta revela com objetividade as descrições observadas a partir das análises dos fenômenos educacionais e socioculturais. Para Bourdieu (2010, p. 26), a construção do objeto de pesquisa não se constrói de forma precipitada, antes deve ser "um trabalho de grande fôlego, que se realiza pouco a pouco, por retoques sucessivos, por toda uma série de correções, de emendas, sugeridos por [...] o conjunto de princípios práticos que orientam as opções ao mesmo tempo minúsculas e decisivas". Nessa orientação teórico-metodológica, além de incentivar a leitura de contos literários, estimulando a contação para o lúdico, incentiva-se também que enquanto professores, busquemos fomentar pesquisas sobre a leitura de contos africanos em aula de línguas, pois assim, entendemos que para além do incentivo à prática da leitura desde cedo, pode-se formar leitores conscientes e com uma formação intercultural que pode focalizar, prioritariamente, o processo de amadurecimento de possíveis percepções de obras africanas. 
Sendo assim, pensar na literatura africana em aula de Língua Portuguesa ou de Língua Inglesa com base intercultural permite conhecer, sob diferentes ângulos, e nas mais variadas situações e relações com a vida social os processos e expressões correspondentes à dimensão da interculturalidade.

\section{Referências}

AGUESSY, H. Visões e percepções tradicionais. In.: AGUESSY, H. Introdução à cultura africana. Trad. Emanuel Godinho, Germiniano Franco e Ana Machado Leite, Lisboa: Edições $70,1997$.

BRASIL. Diretrizes Curriculares Nacionais para a Educação das Relações Étnico Raciais e para o Ensino de História e Cultura Afro-Brasileira e Africana. Brasília, 2008.

BRASIL. LEI 11.645/08. Brasília, 2008.

BOURDIEU, P. O poder simbólico. 14ª ed. Rio de Janeiro: Bertrand Brasil, 2010.

CAMACHO, G. N. Igualdade nas relações Étnico-raciais na Escola: possibilidades e desafios para a implementação da Lei 10.639/2003. In: SOUZA, A. L. S.; CROSO, C. Editora Peirópoles. São Paulo, 2007.

DIOUF, S. A. As tranças de Bintou. Trad. Charles Cosac. Ilustrações Shane W. Evans. São Paulo: Cosac Naify, 2004.

DIOUF, S. A. The Bintou's Braids.

http://www.sylvianediouf.com/bintou_s_braids_2693.htm. Acesso em 10.08.2016

FLORÊNCIO, J. R.; PINHEIRO-MARIZ, J. Ayanda, de Véronique Tadjo: uma narrativa marfinense para uma formação intercultural no ensino de francês para crianças. Revista Lumen et virtus. V. VII, $\mathrm{n}^{\circ} 16$. agosto. 2016. p. 53-74.

FRANCISCO, D. Brasil afro-brasileiro. $2^{\mathrm{a}}$ ed. In: Comunicação, identidade cultural $e$ racismo. Org. FONSECA, Maria N. Soares. Belo Horizonte: Autêntica, 2006.

HOOKS, B. Revista Gazeta de Cuba - Unión de escritores y Artista de Cuba, janeiro.fevereiro de 2005. Tradução do espanhol: Lia Maria dos Santos. Retirado do blog coletivomarias.blogspot.com/.../alisando-o-nosso- cabelo.html, acesso em 10.06.2016

HUNT, P. Crítica teoria e literatura infantil. Trad. Cid Knipel. São Paulo: Cosac Naify, 2010 .

JOUVE, V. A leitura. Trad. Brigitte Hervot. Campinas: Unesp, 2002.

KEITA, F. J'ai lu. Video: < http://www.fatoukeita.net/videos.php, acesso em 21.08.2016

KLEIMAN, A. Oficina de Leitura. 11ª ed. Campinas: Pontes Editores. 2011.

MABIALA, J. Si La Fontaine parlait africain. Illustrateur: Pierre Audemard. Châtenay Malabry: Ed. Acoria. 2009. 
MUNANGA, K. Superando o racismo na escola. Brasília: MEC/BID/UNESCO, 2005.

PARAQUETT, M. Ensino da Língua e Literatura: Política, práticas e projetos. Campina Grande: Bagagem. 2012.

POSLANIEC, C. Vous avez dit littérature? Paris: Hachette Education, 2002

REYES, Y. A Casa Imaginária: Leitura e literatura na primeira infância. $1^{\text {a }}$. Ed. - São Paulo: Global, 2010.

Recebido em: setembro de 2016.

Aprovado em: outubro de 2016. 